\title{
Práticas culturais e comportamento social em informação
}

\author{
Nadi Helena Presser \\ Doutora; Universidade Federal de Pernambuco, Recife, PE, Brasil \\ nadihelena@uol.com.br \\ José Antonio Moreiro González \\ Doutor; Universidad Carlos III de Madrid, Getafe, Espanha \\ jamore@bib.uc3m.es
}

\begin{abstract}
Resumo: O objetivo geral do ensaio é examinar como os aspectos sociais do comportamento humano se conformam no processo de identificação das necessidades, da busca e do uso de informação, na perspectiva de ampliar o debate na Ciência da Informação (CI) sobre perspectivas teórico-metodológicas do paradigma social. Em uma abordagem interdisciplinar, a análise tem seu suporte teórico epistemológico fundamentado em Bauman, especificamente, suas críticas às bases fundadoras do uso do conceito de cultura na sua dimensão social. Na área CI, o objeto de estudo são as teorias desenvolvidas por Chatman, especificamente suas análises sobre os fatores que agem como barreiras à informação em um contexto controlado por normas sociais. Esses referenciais sugerem deslocar a concepção de cultura para além do âmbito da reprodução de um conjunto de normas e valores compartilhados e aceitos coletivamente, para uma posição na qual a ação social é uma dinâmica de transformação do meio social.
\end{abstract}

Palavras-chave: Cultura. Normas sociais. Comportamento em informação. Contexto social.

\section{Introdução}

O estudo social da informação é uma área que tem recebido cada vez mais atenção nas pesquisas desenvolvidas na área da Ciência da Informação (CI). Em um de seus estudos sobre epistemologia e sobre CI, Capurro (2003) observa que o predomínio de um paradigma científico está sempre, em parte, condicionado às estruturas sociais, extensivo, também, a eventos fora do mundo científico, cujo efeito multicausal não só é difícil de prever, como também é difícil de analisar a posteriori. É no âmbito do domínio do paradigma social que este ensaio se fundamenta, razão pela qual o trabalho enfatiza as relações sociais estabelecidas pelas pessoas nos processos de identificação de necessidades, 


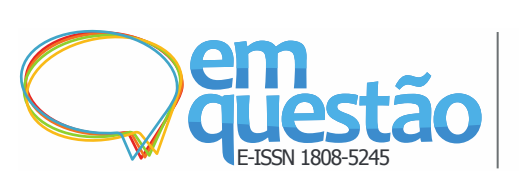

Práticas culturais e comportamento social em informação

Nadi Helena Presser, José Antonio Moreiro González

busca, compartilhamento e uso de informação. Todavia, nesse se atribui importância ao caráter coletivo dessas relações, determinado pelas interações construídas.

Na área da CI, as pesquisas de Chatman (1996, 1999, 2000) têm se destacado por explorar populações dentro de um contexto social. Chatman (1996, 1999, 2000) se concentrou nas barreiras sociais do acesso à informação e delineou seu trabalho com conceitos e proposições para explicar o que ela observou. Uma das conclusões de Chatman (2000) considera que as pessoas, na sua vida cotidiana, vivenciam as informações em resposta às suas necessidades e preocupações diárias e que as circunstâncias pelas quais as necessidades de informações são percebidas dependem do contexto no qual essas pessoas estão inseridas e das relações sociais que lá se estabelecem.

Chatman $(1996,1999,2000)$ descreveu e analisou as relações entre as zeladoras de uma universidade, entre as idosas residentes em uma comunidade de aposentadas e entre um grupo de presas de uma penitenciária de segurança máxima. Assim, desenvolveu uma estrutura conceitual, na qual insere o conceito de vida social, explorando o comportamento em informação na perspectiva da vida vivida em um mundo pequeno ${ }^{1}$. Além disso, usou uma variedade de abordagens teóricas, desenvolveu conceitos como pobreza de informação e recorreu às ciências sociais, a fim de analisar a visão de mundo, as normas sociais e o comportamento normativo em contextos sociais bem delimitados.

Um mundo pequeno para Chatman (1999) é uma sociedade em que as opiniões e as preocupações mútuas são refletidas pelos seus membros, um mundo em que língua e costumes vinculam os seus participantes a uma visão de mundo comum e aceita. Recursos (materiais e intelectuais) são conhecidos e facilmente acessíveis. É um mundo em que há uma consciência coletiva sobre o que é importante e o que não é, quais ideias são relevantes e quais são triviais, em quem confiar e em quem evitar.

$\mathrm{Na}$ sua forma mais verdadeira, um pequeno mundo é uma comunidade de indivíduos que compartilham a mesma opinião da realidade social. Com o aporte de Solomon (1996), a preocupação de Chatman (1999) se move para além da busca, compartilhamento e uso de informação e inclui uma 
compreensão do comportamento em informação, ou seja, como as pessoas definem seus pequenos mundos e como se movimentam por meio deles.

A ideia de que os outros têm uma influência no modo como nos comportamos em um ambiente social encontra apoio na descrição de cultura no âmbito da sociologia, como foi apresentado por Hall (2011) e Bauman (2012). Segundo esses sociólogos, na medida em que as sociedades modernas se tornavam mais complexas, elas adquiriram uma forma mais coletiva e mais social. Em consequência, a sociologia desenvolveu teorias para explicar o modo como os indivíduos são formados subjetivamente por meio de suas participações em relações sociais mais amplas. E, inversamente, explicou o modo como os processos e as estruturas são sustentados pelos papéis que os indivíduos neles desenvolvem. Segundo Hall (2011, p. 31),

Essa 'internalização' do exterior no sujeito, e essa 'externalização' do interior, através da ação no mundo social, constituem a descrição sociológica primária do sujeito moderno e estão compreendidas na teoria da socialização.

Na análise de Bauman (2012), essas são as bases de uma concepção ortodoxa de cultura que somente se tornou dominante porque haviam numerosas áreas do globo com pouca ou nenhuma comunicação entre si que poderiam ser descritas como "totalidades fechadas em si mesmas" (BAUMAN, 2012, p. 30). E havia Estados - nação que promoviam a unificação nacional de línguas, padrões de educação, etc. - preocupados em homogeneizar costumes e memórias coletivas locais para “[...] um conjunto único, comum, nacional, de crenças e estilos de vida." (BAUMAN, 2012, p. 30).

Com base no exposto, o objetivo geral deste artigo é examinar como os aspectos sociais do comportamento humano se conformam no processo de identificação das necessidades, busca e uso de informação. Partindo do pressuposto de que os padrões e as características culturais estão subjacentes e conformam o comportamento em informação das pessoas, examina-se, mais especificamente, a concepção de cultura desenvolvida nas ciências sociais, na perspectiva de debater perspectivas teórico-metodológicas adequadas para ampliar o debate na CI sobre o paradigma social. 
As reflexões deste estudo fazem menção aos trabalhos desenvolvidos na área da CI por Chatman (1996, 1999, 2000), especificamente os resultados de suas pesquisas sobre o comportamento em informação de pessoas em seus contextos cotidianos. As descobertas dessa autora representam um importante potencial que a teoria traz às investigações empíricas sobre comportamento em informação. $\mathrm{Na}$ área da $\mathrm{CI}$, seus fundamentos ampliam nossa compreensão naquilo que define um contexto social específico e fechado em si mesmo.

O conjunto dos conceitos elaborados por Chatman (1996, 1999, 2000) surgiu a partir das suas experiências de campo. Embora os pesquisadores das ciências sociais tenham utilizado bastante a pesquisa de campo como método de coleta de dados, o processo de descoberta de novos fatos ocorre por meio de contato pessoal prolongado com eventos, em um ambiente natural. A etnografia utilizada por Chatman $(1996,1999,2000)$ permitiu a observação desses eventos e o exame dos fenômenos sociais enquanto eles estavam ocorrendo e a observação do comportamento dos respondentes enquanto estavam agindo. As populações estudadas por Chatman $(1996,1999,2000)$ eram, na sua grande parte, formadas por mulheres, especialmente, aquelas que não faziam parte da população social dominante em seus ambientes mais amplos, mas eram dependentes ou controladas por ele.

No campo dos estudos culturais, a análise tem seu suporte teórico epistemológico fundamentado no debate entre alguns autores, com destaque para Bauman (2012), especificamente suas críticas às bases fundadoras do uso do conceito de cultura na sua dimensão social, principalmente na sua abordagem unilateral, na qual uma das suas funções é ordenar o ambiente humano e padronizar as relações entre os seres humanos.

Assim, fazer uma análise na dimensão social é compreender como o contexto social interfere na identificação das necessidades, busca e uso de informação. Segundo Capurro (2003), uma abordagem social na CI não concebe um indivíduo como um ser isolado, mas examina as relações sociais por ele estabelecidas. 


\section{Cultura e vida social}

Segundo Hall (2011), os grandes processos da vida moderna estavam centrados no indivíduo, "sujeito da razão". Destacavam-se, dentre eles, as revoluções científicas que conferiam ao ser humano as faculdades e as capacidades para inquirir, investigar e decifrar os mistérios da natureza.

Tratava-se, conforme Bauman (2012, p. 13), de "Uma filosofia que via o mundo como uma criação humana e um campo de testes para as faculdades do homem.". Ou seja, o universo passava a ser entendido como o ambiente para as atividades, as escolhas, os triunfos e, também, os equívocos humanos.

No renascimento, o ritmo das mudanças fazia o mundo parecer cada vez menos algo feito à semelhança de Deus, cada vez menos eterno,

E o ritmo acelerado das mudanças revelava a temporalidade de todos os arranjos mundanos, e a temporalidade é uma característica da existência humana, não da divina. (BAUMAN, 2012, p. 14).

Assim, Bauman (2012) ressalta que o mundo e a forma como as pessoas nele viviam constituíam uma tarefa, e não algo dado e inalterável. O mundo foi assumindo uma forma cada vez mais humana, tornando-se, aos poucos, segundo Bauman (2012, p. 14), algo feito "à imagem do homem".

No entanto, à medida que as sociedades modernas se tornavam mais complexas, elas adquiriram uma forma mais coletiva e mais social. Às faculdades racionais e ao impulso criativo do ser humano foram reconhecidas as faculdades sociais (BAUMAN, 2012). Assim, se antes o desafio era substituir sempre mais a ordem divina ou natural das coisas por uma ordem feita pelo homem de base racional, agora, essa preocupação convergia em uma outra mais pragmática, de construção da ordem.

Não obstante, o engrandecimento da liberdade humana era complementado pela preocupação com as fronteiras que precisavam ser impostas às ações das pessoas. O conceito de cultura tinha que abarcar a liberdade humana, mas devia abarcar, também, o mecanismo para limitar o escopo dessa liberdade e “[...] a ideia de 'cultura' serviu para reconciliar uma 
série de oposições - em suma, entre a autoafirmação e a regulação normativa." (BAUMAN, 2012, p. 17).

Nessa concepção heterogênea de cultura, estavam presentes duas ideias distintas: criatividade e regulação normativa. A questão central, notada por Bauman (2012), é que entre essas duas forças, mutuamente estranhas e não relacionadas, se ramificaram dois discursos: o produto do primeiro discurso gerou a noção de cultura como lócus da criatividade e da capacidade de se elevar acima do comum - poesia, arte, e demais atividades artísticas; o produto do segundo discurso, por sua vez, apresentou a cultura como instrumento da rotinização, continuidade e ordem social e, nesse caso, liberdade soava como "desvio" e "rompimento da norma". As duas noções de cultura estavam em total oposição, uma negava o que a outra proclamava, uma se concentrava nos aspectos humanos de liberdade que a outra apresentava como anormalidade e restrição.

Foi o segundo discurso que prevaleceu nas ciências sociais. E foi a sociologia a disciplina que teceu a maior crítica ao individualismo racional do ser humano cartesiano, considera Hall (2011). A sociologia localizou o indivíduo nos processos de grupo e nas normas coletivas e desenvolveu teorias para explicar o modo como os indivíduos são formados subjetivamente, por meio de suas participações em relações sociais mais amplas. E, inversamente, explicou o modo de como os processos e as estruturas são sustentados pelos papéis que os indivíduos neles desenvolvem.

Bauman (2012) observa que, durante o século XIX, com o conceito de fatos sociais de Durkheim (1858-1917), se partiu do princípio que o homem era apenas um animal selvagem e que só se tornou humano porque se tornou sociável, ou seja, foi capaz de aprender hábitos e costumes característicos de seu grupo social para poder conviver no meio deste.

A este processo de aprendizagem, Durkheim $(2007)^{2}$ chamou de "socialização", tudo aquilo que serve para orientar como uma pessoa deve ser, sentir e se comportar. É esse conjunto de diretrizes ou normas que ele chamou de fatos sociais. Entretanto, um fato social, segundo Durkheim (2007), atende a três características: generalidade, coercitividade e exterioridade. 
A generalidade significa que os fatos sociais existem não para um indivíduo específico, mas para a coletividade. A coercitividade é uma característica relacionada à força dos padrões culturais do grupo que os indivíduos integram. Estes padrões culturais são fortes de tal maneira que obrigam os indivíduos a cumpri-los. E, por último, a exterioridade é a característica que transmite o fato de esses padrões de cultura serem exteriores ao indivíduo, ou seja, ao fato de virem do exterior e de serem independentes da sua vontade.

Emergiu, então, uma concepção social do ser humano que passou a ser definida no interior de grandes estruturas sustentadoras da sociedade moderna. Segundo Hall (2011), a noção de sujeito sociológico refletia a complexidade do mundo moderno e a consciência de que esse núcleo interior do sujeito não era autônomo, mas formado na relação com outras pessoas que mediavam para ele os valores, os sentidos e os símbolos dos mundos que ele habitava. Ao examinar essa concepção de cultura como estrutura, Bauman (2012) salienta que a aproximação estruturalista à cultura resulta em um conjunto de regras generativas, historicamente selecionadas pela história humana que governam ao mesmo tempo a atividade mental e prática dos indivíduos, contemplados como seres epistêmicos e a gama de possibilidades nas quais essas atividades podem operar.

Todavia, cultura não é apenas a soma descritiva dos costumes partilhados coletivamente, como ela tende a ser abordada na teoria tradicional. A cultura, como vista por pensadores como Simmel (1968) e Lévi-Strauss (1975), entre outros, é tanto um agente de desordem quanto um instrumento de ordem. Segundo Bauman (2012, p. 28), “[...] um fator tanto de envelhecimento e obsolescência quanto de atemporalidade.".

Na sociologia, Simmel (1968) preferiu extrair o conceito de cultura da tragédia grega e não do emaranhado puramente lógico. Segundo esse sociólogo, a cultura vem a ser criada pelo encontro de dois elementos, nenhum dos quais a contém por si mesmos: entre a vida subjetiva, que é agitada, mas temporalmente finita; e seus conteúdos que, uma vez criados, são estacionários. Em meio a esse dualismo vive a ideia de cultura. 
Na concepção de Simmel (1968 3 apud BAUMAN, 2012), a cultura se expressa e se realiza na religião, na ciência, na tecnologia, nas obras de arte, nas leis e em uma infinidade de outras. Embora surjam a partir dos processos da vida, esses conteúdos não compartilham seu ritmo agitado, mas sim, adquirem identidades estáveis e legitimidade próprias. Todavia, a sedimentação das formas e a sua erosão é um processo que jamais cessa.

Para Bauman (2012), as ideias seminais de Simmel (1968) pressupõem que a sociedade vive sobre o caos e que ela própria é o caos. A cultura, nessa perspectiva, é tanto um agente de desordem quanto um instrumento de ordem. Como explica Bauman (2012), a cultura, nessa perspectiva, tende a ser vista como um fator tanto de envelhecimento e obsolescência quanto de atemporalidade, de maneira que o ponto não é tanto a perpetuação da cultura, mas em garantir as condições para futuras mudanças.

O paradoxo da cultura, segundo Simmel (1968), é entre sujeito-objeto: a vida subjetiva que, em seu fluxo contínuo pressiona a partir de si mesma no sentido de sua realização. Mas não pode alcançar, do ponto de vista da ideia de cultura, essa realização a partir de si mesma, mas somente através daquelas configurações agora totalmente estranhas e cristalizadas em uma unidade fechada em si mesma. A cultura nasce, enfatiza Simmel (1968), quando dois elementos se reúnem e nenhum deles a contém em si: a alma subjetiva e a criação espiritual objetiva.

Bauman (2012) também considera Lévi-Strauss (1975) como pensador que contribuiu para destruir a ideia ortodoxa de cultura. $\mathrm{O}$ grande mérito de Lévi-Strauss (1975) foi mostrar o fim da atribuição unilateral da cultura. Para Bauman (2012), Lévi-Strauss (1975) forneceu elementos teóricos para a cultura não ser mais vista como uma restrição à inventividade humana, nem como reprodução monótona da vida. A cultura para Lévi-Strauss (1975) era em si uma força dinâmica. 


\section{As barreiras à informação em um contexto controlado por normas sociais}

Já que o foco das investigações de Chatman $(1996,1999,2000)$ girava em torno das necessidades de informação das pessoas que viviam marginalizadas, suas estruturas conceituais culminaram na noção de cultura como controle social. $\mathrm{Na}$ sua definição de pobreza de informação, Chatman, (1996, 2000) postulou que uma pessoa pobre em informação não se caracterizava tanto por sua pobreza econômica, mas se mostrava mais ligada a um conjunto de atitudes e normas socialmente determinadas, as quais caracterizavam uma experiência de vida empobrecida de informação.

Em outro estudo de Chatman (2000) com as zeladoras de uma universidade, ela identificou que as mesmas acreditavam fortemente na sorte, "o que acontece, acontece" (CHATMAN, 2000, p. 5, tradução nossa). Ou, dito de outra forma, qual seria o propósito de elas tentarem melhorar sua situação, se, no fim, tudo seria resolvido pelo destino? Não era vantajoso para elas envolverem-se, exporem-se, gastarem energia pessoal, recursos financeiros, ou até mesmo nutrirem sonhos otimistas, se, no final, suas vidas eram seladas pelo destino. Em suma, os resultados da investigação com as zeladoras indicaram que o comportamento em informação abrange não somente o interesse por informação (a informação que se procura), mas pode também envolver desinteresse por informação devido aos padrões culturais vigentes. Assim, Chatman $(1996,2000)$ definiu um mundo de pobreza de informação como aquele em que uma pessoa não deseja ou não sabe resolver um problema crítico. Pessoas definidas como pobres em informação percebem-se desprovidas de quaisquer fontes de informação que poderiam ajudá-las. Em não sendo uma condição isolada, a pobreza de informação é definida pelos comportamentos de autoproteção que são adotados com base nas normas sociais.

As normas sociais, segundo Chatman (2000), são os padrões habituais que tomam lugar dentro de um ambiente específico. O seu objetivo é dar um senso de equilíbrio ao mundo e, por isso, funcionam como códigos de comportamento. O papel das normas é definir as informações que são legitimadas para buscar e apropriadas para compartilhar. As normas sociais estabelecem, assim, os limites iniciais (e para alguns, duradouros) dentro dos 


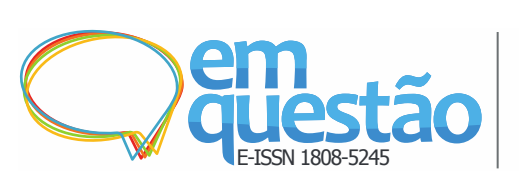

Práticas culturais e comportamento social em informação

Nadi Helena Presser, José Antonio Moreiro González

quais uma pessoa constrói sua vida e, consequentemente, define suas necessidades de informação.

No seu estudo com as idosas vivendo em uma casa de repouso, Chatman (1996, 2000) identificou que as mesmas não estavam envolvidas na busca ou na partilha de informações porque elas desejavam mostrar uma aparência de normalidade. Em alguns casos, a sua impressão de bem-estar significava a sua capacidade de manter certo grau de independência e autonomia, ou revelava seus medos de enfrentar a possibilidade real de expulsão de sua comunidade de aposentados.

Os limites deste mundo aparentemente isolado de apoio mútuo e de ajuda, constituído de uma pequena sociedade em que o envelhecimento das mulheres foi impulsionado por comportamentos de autoproteção, em um esforço para transparecer tudo normal (enganando aos outros e a si mesmas), enquanto suas vidas iam desfalecendo levou Chatman (1996, 2000) aos conceitos de sigilo e engano no comportamento em informação.

Sigilo significa proteger-se contra a exposição indesejada, ou seja, segundo Chatman $(1996,2000)$, é uma tentativa deliberada de não informar aos outros sobre suas verdadeiras preocupações. Chatman (1996) recorre a Simmel (1950) que argumenta que o sigilo, no sentido da ocultação da realidade por meios negativos ou positivos, é o desejo que as pessoas têm de reivindicar uma dimensão íntima ou privada da vida que é exclusivamente delas. Dito de outra maneira, ocultar uma informação é um mecanismo no qual uma pessoa está em defesa de seus espaços privados.

Um segundo fator associado com a pobreza de informação é o engano. Assim, segundo Chatman (1996), o engano é uma tentativa deliberada de atuar, isto é, de se engajar em atividades em que a realidade vai sendo conscientemente distorcida. Isso é um processo destinado a esconder a verdadeira condição, fornecendo informações falsas e enganosas, o que significa menor possibilidade de recebimento de informações úteis. Considerem-se, aqui, os casos das crianças que sofrem de abuso sexual, apontados nos estudos de Mikkelsen, Guthiel e Emens (1992) e das esposas vítimas de agressão, como apontado por Dutton e Hemphill (1992). 
Enquanto o sigilo foi definido por Chatman (1996, 2000) como um processo de não ser receptivo às informações, engano denota uma tentativa deliberada de representar uma falsa realidade social. Desvinculado da verdade, o engano é o envolvimento em atividades em que a realidade pessoal é consciente e forçadamente distorcida.

Determinadas a se protegerem, as zeladoras e as aposentadas se envolviam em comportamentos de autoproteção, que definiam os limites de um mundo de pobreza de informação. A teoria da pobreza de informação de Chatman (2000) explica maneiras pelas quais as pessoas definem suas experiências de vida a fim de sobreviver em um mundo no qual não há confiança para expressar suas verdadeiras necessidades de informação. Assim, segundo Chatman (2000), quando as preocupações e os problemas se apresentam e quando a informação é reconhecida como potencialmente útil, mas é ignorada, as pessoas vivem em um mundo de informações empobrecidas.

Outra contribuição significativa de Chatman (1999) em explorar populações dentro de um contexto social é a constatação de que valores partilhados transmitem a noção de uma visão de mundo: a aceitação de certas maneiras de falar, de se comportar, de aceitar ou de rejeitar informações. Chatman (1999) definiu visão de mundo como um conjunto de crenças de membros que vivem em um mundo ou contexto específico e, de certa forma, bem delimitado.

A realidade informacional, por exemplo, que Chatman (1999) descreveu da vida na prisão é a base de uma realidade compartilhada. As presas mostraram formas padronizadas de apresentarem-se umas às outras. Um elemento que mantém esse mundo unificado, segundo Chatman (1999, 2000), é o controle social. Os horizontes desse mundo são determinados por normas sociais. Apoiada em Redfield (1943), Chatman (1999) afirma que esse é um mundo em que as formas de olhar as coisas estão em conformidade com os padrões acordados.

$\mathrm{Na}$ análise de Chatman (1999), o que faz uma informação potencialmente notável é que ela é produzida em um contexto específico, para utilização neste contexto e, consequentemente, ela facilmente se ajusta à 
realidade da vida cotidiana. Mesmo que dúvidas possam permanecer sobre a verdadeira natureza da informação, sua capacidade de moldar uma visão de mundo coletiva quase não pode ser questionada.

Portanto, uma informação não significa nada se não é parte de um sistema de ideias afins, expectativas, padrões e valores. Por exemplo, um tema consistente de conversa entre as presas diz respeito ao estatuto de sua liberdade condicional. Na prisão, a liberdade condicional é um tema que carrega o interesse do mais alto grau. As conversas giram em torno de quem está prestes a sair, como se consegue viver na prisão para reduzir o seu tempo de encarceramento e para quem foi recusada a liberdade condicional. É esse sistema comum de ideias de uma experiência compartilhada que dá significado para o que ocorre.

Assim, considerando que os membros de um pequeno mundo gostem de certa ordem de funcionamento e de coisas que eles podem entender facilmente, informação relevante é aquela que é clara o suficiente para dar significado sensível às coisas. Segundo Chatman (1999), quanto mais uma pessoa pode entender o óbvio, mais ela está disposta a permitir que novas informações influenciem o seu mundo.

\section{A cultura como uma força dinâmica de continuidade e descontinuidade}

Como vimos, a ideia de cultura, tal como apropriada e utilizada pela ciência social ortodoxa fora reduzida para cobrir apenas o aspecto previsível, rotineiro e institucionalizado do comportamento humano. Como nota Bauman (2012), nessa atribuição unilateral, o fenômeno da cultura foi acomodado com sucesso no campo da "realidade transcendental", no qual pode ser tratado da forma adequada pela ciência positivista.

Chatman (2000) definiu como comportamento normativo a imposição de modos de vida por meio de normas sociais. O que Chatman (2000) observou é que essas normas sociais não têm um valor de verdade, senão um modo determinado de interpretação que foi aceita e retida o suficiente, conferindo-lhes muitas vezes uma espécie de função transcendental pura a coisas que tiveram, inicialmente, funções regulativas para a vida. 
O que se lê nos estudos de Chatman $(1996,1999,2000)$ é que as normas sociais impelem uma pessoa a não se submeter a uma observação crítica dos membros do seu mundo. É nessa arena pública que o comportamento privado é julgado, incluindo comportamento de busca de informação adequado ou não. Todavia, impelidas a se protegerem, as pessoas omitem e distorcem informações.

Essencialmente, então, quais são as características que são relevantes para a discussão sobre cultura em informação na área da CI? O que se lê dos trabalhos desenvolvidos por Chatman $(1996,1999,2000)$ é que essa imposição de formas de vida por meio de normas sociais, às quais as pessoas vão recorrendo umas as outras para se garantir, produz pessoas sem capacidade de reação, um tipo de efeito paralisante sobre a vida, tentando reafirmar o porquê das coisas não mudarem ou serem difíceis de mudar.

Todavia, considere-se a afirmação de Bauman (2012, p. 298) de que “A cultura só pode existir como crítica prática e intelectual da realidade social existente.". Decorre dessa afirmação que o pressuposto da cultura é o de que a existência real, a única já realizada, sedimentada e objetivada não é nem a única, nem a mais autorizada, muito menos é o único objeto do conhecimento interessado. O caráter inacabado, incompleto e imperfeito do real sustenta o status da cultura e manifesta o seu principal atributo: sua capacidade crítica, baseada em sua supremacia sobre o real.

O que se conclui com Bauman (2012), Simmel (1968) e Lévi-Strauss (1975) é que a cultura é a condição humana em que o conhecimento da realidade está aqui para ser descoberto e aprendido; em vez de acreditar que o significado está ali, pronto e completo. A cultura, portanto, questiona, constantemente, a sabedoria, a serenidade e a autoridade que o real atribui a si mesmo. A cultura como mera continuidade de padrões de vida é impensável sob qualquer outra forma que não a cadeia infindável de permutas e inovações.

Portanto, evidenciar a cultura nos processos de construção, comunicação e uso da informação implica considerar a produção histórica e social dos significados construídos em um determinado grupo social. Apreender o usuário de informação como culturalmente constituído implica operar dentro de uma 


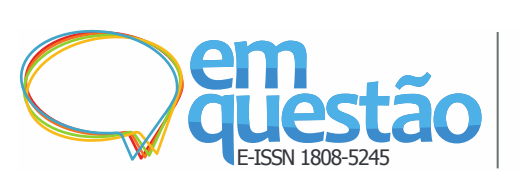

perspectiva em que a pessoa nunca é idêntica a si mesma por todo o sempre. Assim, embora determinados grupos tentem permanentemente impor práticas sociais como certas, os movimentos de contestação também são permanentes.

Sem desafiar a busca científica da verdade como uma correspondência entre conhecimento e realidade, Bauman (2012) realça que essa concepção de cultura se recusa a consentir com a atitude limitadora da ciência positivista e sua pretensão de que somente a realidade já realizada, empírica, pode ser admitida como padrão do conhecimento válido. A cultura como uma condição humana admite uma multiplicidade de realidades, mundos possíveis, potenciais, desejáveis, ansiados, mesmo que ainda improváveis. É nesse sentido que a cultura é singularmente humana. Bauman (2012) salienta que somente o ser humano, entre todas as criaturas vivas é capaz de desafiar sua realidade e reivindicar um significado mais profundo, a justiça, a liberdade, o bem, seja ele individual ou coletivo.

Assim, além de identificar os padrões culturais subjacentes ao comportamento em informação, o que se defende neste ensaio é a importância de se colocá-los em questão. Isso significa, por exemplo, investigar as condições e as circunstâncias nas quais determinados normas ou padrões nasceram, nas quais circunstâncias se desenvolveram e ou se modificaram. Em uma abordagem social, não faz sentido descobrir somente quais as percepções que determinadas pessoas têm sobre o processo informacional, mas também como observou Frohman (1992), desvelar outras relações de poder que conformam um contexto, no qual a pessoa é apenas uma parte.

$\mathrm{Na}$ perspectiva trágica da existência humana, o contexto social não é naturalizado e não diz respeito apenas à descrição e análise de fatos e acontecimentos. Hjørland (2004) salienta que o ponto de vista sociocognitivo enfatiza a internalização de signos produzidos culturalmente e como símbolos e processos cognitivos são mediados culturalmente, historicamente e como significados são socialmente construídos.

$\mathrm{Na}$ área da CI, esses referenciais apontam para a necessidade de se deslocar a concepção de cultura para além do âmbito da reprodução de um conjunto de normas, valores, regras e costumes, para uma posição onde a ação 
social é uma dinâmica de transformação do ser social, bem como de mudanças sociais. O contexto social, nessa abordagem metodológica diz respeito aos aspectos que produzem e modificam comportamentos, possibilitando o aparecimento e o desaparecimento de determinados padrões de construção, comunicação e uso da informação.

Isso pressupõe expandir as discussões no que se refere ao paradigma social, ainda que sem pretensões de exaustividade, evidenciando como a cultura conforma o comportamento em informação dos produtores e usuários de informação e, indo além, na investigação da gênese das normas sociais, visando também uma mudança no comportamento em informação das pessoas. A cultura é um dos operadores conceituais importantes para os estudos dos fluxos informacionais, já que o processo de construção, comunicação e uso da informação se localiza na estrutura empírica e nas relações sociais, quanto em um sentido epistemológico, por transformar os modos de conhecimento mediados pela informação.

Visto de uma perspectiva de mudança, isso significa que os valores de uma sociedade podem ser reinterpretados para novos fins, requisitados de maneira nova, transformados e redirecionados para uma nova utilidade. Considerando que a utilidade de um costume social se constitui em uma condição para a vida, o pesquisador, nessa perspectiva, iria buscar o surgimento desse costume compreendido nem como realidade, nem como representação da realidade, mas como algo que foi criado e que lhe imprimiu o sentido de uma função.

Note-se que as investigações de Chatman $(1996,1999,2000)$ constaram que uma informação é mais relevante quando está em conformidade com o senso comum. A segunda questão que se coloca é reconhecer que, como especialistas em informação também somos atores centrais de um mundo social.

Hjørland e Albrechtsen (1995) salientam que o melhor modo de compreender a informação na CI é estudar domínios do conhecimento como comunidades de reflexão ou discussão, que fazem parte da divisão do trabalho na sociedade. Segundo esses autores, organização do conhecimento, estrutura, padrões de cooperação, linguagem e formas de comunicação, sistemas de 
informação e critérios de relevância são reflexões dos objetos de trabalho dessas comunidades e seus papeis na sociedade.

O paradigma de análise de domínio é assim, segundo Hjørland e Albrechtsen (1995), um paradigma social. Assim, um domínio é conformado por práticas sociais que expressam ou comunicam um significado compartilhado comum.

Tome-se como exemplo um sistema de organização e representação da informação, práticas tão comuns na CI. Esses códigos de significado, tomados em seu conjunto, constituem os discursos de um domínio. Consequentemente, os especialistas de domínio também definem as informações importantes de se prestar atenção e as que não são e, assim, se constituem nos atores legítimos para controlar o fluxo de informações do seu mundo social. Hjørland (2004) reputa que uma pedra contém algumas informações para os geólogos, outras informações para os arqueólogos. Ou seja, diferentes profissionais descrevem objetos informativos de diferentes formas e organizam suas descrições de acordo com critérios de domínio específico.

Assim, o que se lê em Hjørland (2004) é que o significado de um objeto reside não no objeto em si, mas é produto da forma como esse objeto é socialmente construído. A informação é, portanto, um fenômeno emergente, que é sempre relativo a certos critérios coletivos definidos e acordados em uma comunidade.

O mundo dos produtores de informação e o mundo dos usuários são distintos, cada qual com suas normas e costumes. A existência de dois mundos pode ser um obstáculo à busca e ao compartilhamento de informações. Os especialistas de domínio, devido ao seu status, podem reforçar a pobreza de informação se não acolherem e se não levarem em consideração que os usuários pertencem a diferentes culturas, estruturas sociais e domínios de conhecimento.

O principal desafio para cientistas informacionais é, assim, compreender as necessidades do usuário a partir de uma perspectiva social. Como as pessoas usam a informação para formular, definir ou reivindicar suas realidades sociais, parece ser o foco principal para conduzir esforços de investigação sobre comportamento em informação. 


\section{Considerações finais}

Neste ensaio examinou-se como os aspectos sociais do comportamento humano se conformam no processo de identificação das necessidades, busca e uso de informação, na perspectiva de debater perspectivas teórico-metodológicas adequadas para ampliar o debate na CI sobre o paradigma social.

Como foi visto, as teorias de Chatman $(1996,1999,2000)$ dizem respeito a um determinado tipo de informação que se destina a responder às necessidades dos indivíduos dentro de um contexto social específico. São as normas sociais desse mundo que delimitam e indicam que tipos de informações são compartilhadas e quais são retidas.

As normas sociais são costumes, tradições, regras, valores e todos os outros critérios de conduta que são padronizados em um meio social e que afetam a troca de informações, visto que elas definem parâmetros e agem como pontos de referência em torno do processo informacional.

Introduzir o aporte teórico metodológico dos estudos culturais contribuiu, em primeiro lugar, para reconhecer que cultura não é apenas a soma descritiva dos costumes. Com o universo da tragédia grega, vemos a cultura como uma condição humana que inclui, além da rotina derivada das normas sociais, um convite à mudança. Isso significa lançar mão do intelecto para criar condições para expansão da vida, indo além da tendência de auto conservação ou da simples adaptação.

Nesse caso, caberia ao pesquisador se ocupar com a origem das normas sociais que conformam o comportamento normativo identificado por Chatman (2000), como algo que foi criado pelo homem em determinadas circunstancias para determinados fins. Ao tomar as normas sociais como interpretações humanas, somente assim os pesquisadores podem responder questões do tipo: sob que condições determinados grupos sociais inventaram para si determinados padrões culturais? É a partir dessas questões e dos pressupostos aqui discutidos que os estudos culturais relacionados aos fluxos informacionais poderão olhar para a história, sociologia, filosofia e demais disciplinas que caracterizam a CI como ciência interdisciplinar. 
Assim, além das perspectivas teóricas, questões metodológicas envolvidas também devem ser ressaltadas. Chatman (1996, 1999, 2000) adotou a etnografia como principal método de coleta de dados. A sua utilidade está na oportunidade que fornece para uma variedade de pontos de vista e para compreender as interações sociais cotidianas de pessoas. Na prisão, por exemplo, estar com as presas depois do horário de expediente dos profissionais de apoio pode significar a busca de uma visão razoavelmente mais próxima da vida cotidiana.

\section{Referências}

BAUMAN, Z. Ensaios sobre o conceito de cultura. Rio de Janeiro: Zahar, 2012.

CAPURRO, R. Epistemologia e ciência da informação. In: ENCONTRO NACIONAL DE PESQUISA EM CIÊNCIA DA INFORMAÇÃO, 5., 2003, Belo Horizonte. Anais... Belo Horizonte: UFMG, 2003.

CHATMAN, E. A. Framing social life in theory and research. The New Review of Information Behaviour Research, London, v. 1, p. 3-17, Dec. 2000.

CHATMAN, E. A. The impoverished life-world of outsiders. Journal of the American Society for Information Science, New York, v. 47, n. 3, p. 193-206, 1996.

CHATMAN, E. A. Theory of life in the round. Journal of the American Society for Information Science, New York, v. 50, n. 3, p. 207-217, 1999.

DURKHEIM, E. As regras do método sociológico. 3. ed. São Paulo: Martins Fontes, 2007.

DUTTON, D. G.; HEMPHILL, K. J. Patterns of socially desirable responding among perpetrators and victims of wife assault. Violence and Victims, New York, v. 7, p. 29-39, 1992.

FROHMAN, B. The power of images: a discourse analysis of the cognitive viewpoint. Journal of Documentation, London, v. 48, n. 4, p. 365-386, 1992.

HALL, S. A identidade cultural na pós-modernidade. 11. ed. Rio de Janeiro: Ed. DP\&A, 2011.

HJØRLAND, B. Domain analysis: a socio-cognitive orientation for information science research. Bulletin of the American Society for Information Science and Technology, Silver Spring, v. 30, n. 3, p. 17-21, 2004. Disponível em: 
<http://onlinelibrary.wiley.com/doi/10.1002/bult.312/pdf>. Acesso em: 1 mar. 2017.

HJØRLAND, B.; ALBRECHTSEN, H. Toward a new horizon in information science: domain-analysis. Journal of the American Society for Information Science, Washington, v. 46, n. 6, p. 400-425, July 1995. Disponível em: <http://onlinelibrary.wiley.com/doi/10.1002/(SICI)10974571(199507)46:6\%3C400::AID-ASI2\%3E3.0.CO;2-Y/pdf>. Acesso em: 4 mar. 2017.

LÉVI-STRAUSS, C. Antropologia estrutural. Rio de Janeiro: Tempo Brasileiro, 1975.

MIKKELSEN, E. J.; GUTHIEL, T. G.; EMENS, M. False sexual abuse allegations by children and adolescents: contextual factors and clinical subtypes. American Journal of Psychotherapy, New York, v. 46, p. 556- 570, 1992.

REDFIELD, R. Rural sociology and the folk society. Rural Sociology, Knoxville, v. 8, n. 1, p. 68-71, 1943.

SIMMEL, G. On the concept and the tragedy of culture. In: SIMMEL, G. Conflict in modern culture and other Essays. New York: Teachers College Press, 1968.

SIMMEL, G. The sociology of Georg Simmel. Glencoe: The Free Press, 1950.

SOLOMON, P. Information behavior in sense making: a three-year case study of work planning. Journal of the American Society for Information Science, Washington, p. 1-28, 1996.

\title{
Cultural practices and social behavior in information
}

\begin{abstract}
The essay aims to investigate how the social aspects of human behavior shape the process of identifying the needs, the search and the use of information. The idea is to expand the debate in Information Science (IS) regarding the theoretical and methodological perspectives of the social paradigm. With an interdisciplinary approach, the analysis is based on the theoretical-epistemological contribution of Bauman, more specifically, on his critique of the fundamental bases of the culture concept in its social dimension. These assumptions are closer to IS based on the theoretical approaches of Chatman, which analyze the factors that operate as barriers to information in environments dominated by social norms. These referents suggest moving the concept of culture beyond the scope of reproducing a set of collectively accepted norms and values, to a position where social action becomes a dynamic transformation of the social environment.
\end{abstract}


Práticas culturais e comportamento social em

informação

Nadi Helena Presser, José Antonio Moreiro González

Keywords: Culture. Social norms. Behavior in information. Social context.

Recebido: 25/03/2017

Aceito: $13 / 05 / 2017$

${ }^{1}$ Em inglês, "Life in the Round". O sentido que a autora tenta transmitir é o de uma vida restrita a um ambiente específico, um contexto bem delimitado.

${ }^{2}$ Obra publicada originalmente em francês, em 1988, sob o título Les règles de la méthode sociologique. A primeira edição no Brasil foi publicada em 1995.

${ }^{3}$ SIMMEL, G. The conflict in modern culture. New York: Teachers College Press, 1968. Apud Bauman, 2012. 